\title{
The Application of Data Mining in Electronic Commerce Ying Chen
}

(NanChang Institute of Science \& Technology, Nanchang, China, 330108)

\author{
Keywords: E-commerce; Data mining; Application
}

\begin{abstract}
With the maturity of network technology and database technology, the global traditional business is experiencing a major change, moving to e-commerce at full speed. E-commerce is a new business model in the commercial field. It is a modern business mode with network as the platform and modern information technology as the means, focusing on economic benefit and its ultimate goal is to realize the networking, intelligentization and automation of business activities,. The emergence of e-commerce has changed the business philosophy, management methods and means of payment, has brought great changes to the various fields of society. With the rapid development of network technology and the improvement of social information level, e-commerce shows great market value and development potential.
\end{abstract}

\section{Introduction}

In the era of information and knowledge economy, with the rapid development of network technology and the improvement of social information level, the traditional trade is experiencing a major change, e-commerce shows great market value and development potential. E-commerce is a new business model in the commercial field. It is a modern business model with network as a platform, modern information technology as a means, focusing on economic efficiency. Its ultimate goal is to realize the networking, automation and intelligentization of business activities. The emergence of e-commerce has changed the business philosophy, management methods and means of payment, has brought great changes to the various fields of society. When e-commerce is applied in the enterprise, the enterprise information system will generate a lot of data, these surge of electronic data means that people face the problem of "rich data but lack of knowledge" .

After the appearance of "data explosion but the lack of knowledge" phenomenon, how can not be overwhelmed by the vast ocean of information, and find useful information and knowledge from which timely. Therefore, a new generation of technology and tools are needed to carry out reasonable and higher level of analysis, to make inductive reasoning, and explore the potential mode, extract useful knowledge to help e-commerce business decision-makers to adjust the market strategy, make business forecast, to make the right decisions, so as to improve information utilization, reduce risk, bring huge profits to the enterprise. Data mining is the data processing technology to adapt to these needs of development.

\section{Data Mining}

Data mining is one kind of information processing technology combining database, artificial intelligence and statistics and other disciplines. Through the effective mining of large amounts of data accumulated in history, attempt to extract previously unknown but useful knowledge from these data. Using pattern recognition, statistics, and mathematical techniques to screen and find new ways of discovering new meaningful relationships, patterns, and trends. In other words, Data Mining is a non-trivial process of extracting potentially useful and understandable information and knowledge that people don't know and implied in the content from a large number of incomplete, noisy, fuzzy random application of the actual data. The data mining process is shown in Figure 1. 


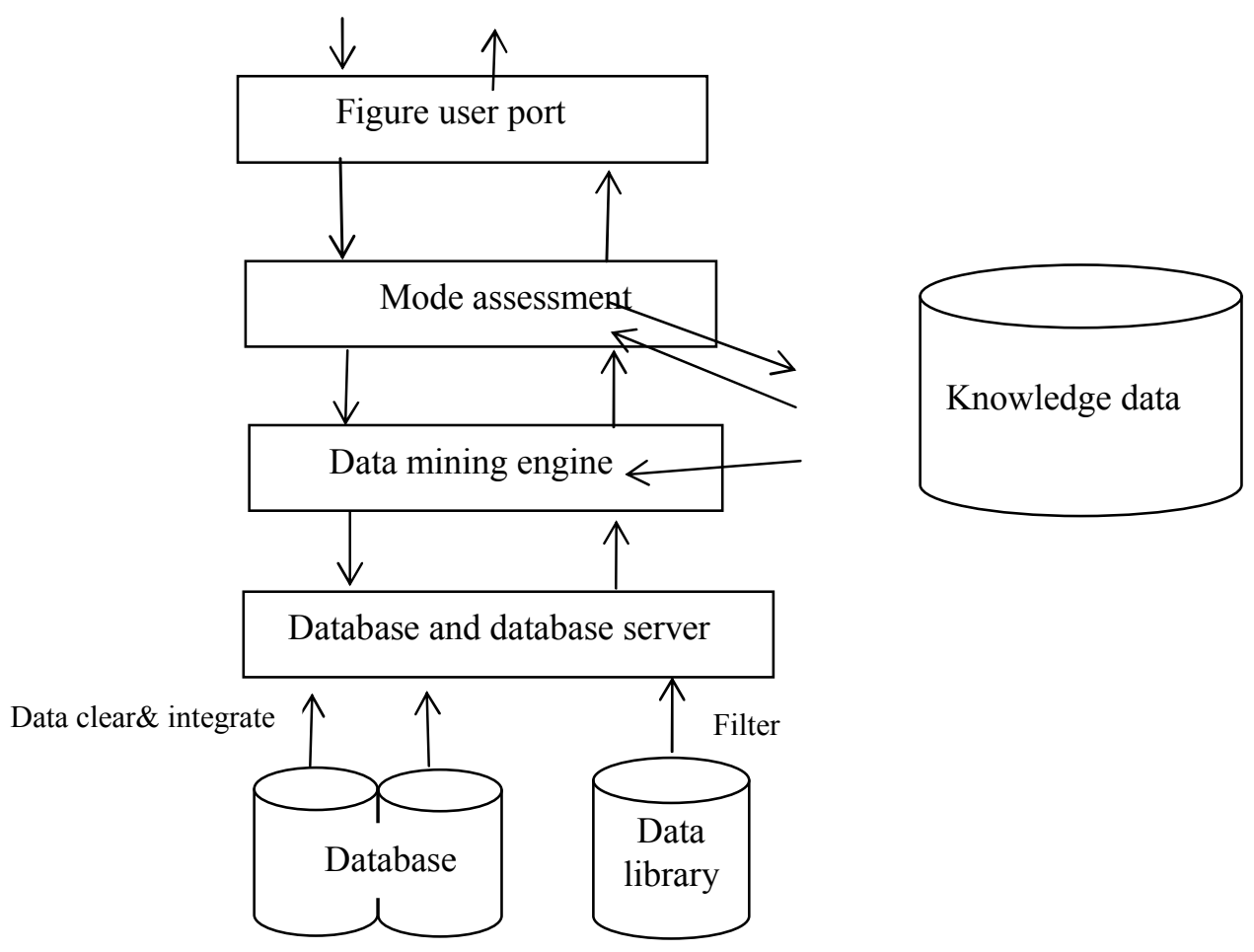

Figure 1 database mining flow image

Data mining and traditional data analysis (such as query, report, online analysis and processing). Difference is that data mining is mining information and find the knowledge under the premise of the absence of a clear assumption. Information from data mining should have the previous knowledge, effective and practical three characteristics. The previously unknown information refers to information that is not expected beforehand, that is to say, date mining is to to find information or knowledge that can not be found by intuition alone, and may even be information or knowledge contrary to intuitive. The more surprise, there may be more useful. And it is a non-trivial process that the mining process is not linear, but repeated and cyclic, the knowledge mined is not easy to be obtained through simple analysis, is likely to be implied in the internal of the surface phenomenon, so it needs to apply some special data mining tools dealing with large data, obtained from a large number of comparative analysis of data.

\section{Main Methods of Data Mining}

Data mining combines the theory and technology of databases, artificial intelligence, machine learning, statistics and other fields. The typical data mining methods are classification, association rule analysis, clustering analysis and isolated point analysis.

Classification. Classification is to find a category of conceptual description, which represents the overall information of such data, that is, the description of the class, generally expressed by rules or decision tree model. In fact, by analyzing the data in the sample database, make an accurate description for each category or create an analysis model or dig out the classification rules, and then use this classification rules to classified other records in the database.

Association rules analysis. Association rule analysis is used to discover association rules. If the value of two or more data items recur and the probability is high, it exists in a certain association, you can establish the association rules of the data items, generally using "support" and "confidence" the two threshold to eliminate those useless association rules. Association rule analysis can find features such as "90\% of customers buying goods A at the same time buying goods B".

Cluster analysis. The cluster analysis object is a set of unclassified records, and is is unknown that these records should be divided into several categories in advance. Clustering is through the analyzing the database record data, according to a certain classification rules, reasonably dividing 
records to determine the type of each record. The classification rules it uses are determined by the clustering analysis tool. Using different clustering methods, there may be different partitioning results for the same set of records.

Isolated point analysis. The data in the database often have some anomalous records, which are called isolated points, often including many potential knowledge, such as anomalies in the class, the special case do not meet the rules, the deviation between the observed results and model predictions, the value changing with time and so on. The basic method of isolated point analysis is to find the difference between the observed results and the reference.

\section{Application of Data Mining in Electronic Commerce}

\section{Optimize enterprise resources}

Saving costs is the key to corporate profitability. Based on the data mining technology, timely, comprehensively and accurately grasp enterprise resource information, by analyzing the historical financial data, inventory data and transaction data, you can find the key points of enterprise resource consumption and the proportion of input and output of the main activities, to provide decision-making basis for optimizing the allocation, such as reducing inventory, improve inventory turnover, improve capital utilization.

\section{Manage customer data}

With the importance of "customer-centric" business philosophy, analyzing, understanding and guiding customer needs have become an important business issue. Based on data mining technology, enterprises will maximize to use customer resources, carry out customer behavior analysis and prediction, make the customer classification. It is conductive to analyze customers profitability, find potential valuable customers, and carry out personalized services, to improve customer satisfaction and loyalty. Through the mining of Web resource, to understand the customer's buying habits and interests, thereby improving the site structure design, launch personalized web pages to meet the different customers.

\section{Assess business credit}

Poor credit status is a prominent problem affecting the business order, has caused widespread concern in the world. Due to the phenomenon of online fraud, enterprise financial "false" phenomenon is becoming increasingly serious, credit crisis has become an important factor restricting the development of e-commerce. Using data mining technology to track business, carry out the enterprise's asset valuation, profitability analysis and development potential forecast, to build a sound security system, the implementation of online monitoring, strengthen online transactions and online payment security management. Based on the data mining credit evaluation model, mine the transaction history data, to find the customer's transaction data characteristics, establish customer credibility level, effectively prevent and resolve credit risk, improve level and ability of enterprise to screen credit and manage risk.

\section{Determine the abnormal events}

In many business areas, unusual events have significant business value, such as customer churn, bank credit card fraud, and mobile free default. Through the singular point analysis in data mining, we can quickly and accurately identify these abnormal events, and provide the basis for decision-making of enterprises and reduce the unnecessary losses of enterprises.

\section{Conclusion}

Data mining highly automatically analyze and reason a large amount of information in e-commerce, digging out potential models, predicting customer behavior, helping business decision makers to adjust market strategies, reduce risk, and make the right decisions. Data mining is the hotspot in the field of data mining in recent years. Applying it to e-commerce using it's technical knowledge will solve many practical problems, has rich academic value. The combination of data mining technology and e-commerce organically will help enterprises to more effectively identify the target market, improve decision-making, gain competitive advantage, have a very broad application 
prospects, so that e-commerce sites are more competitive, so as to bring more benefits to enterprises. Web data mining for e-commerce can find a lot of data behind the hidden knowledge to guide businesses to improve sales, improve enterprise customer relationships, improve the efficiency of the site, improve system performance, have a good development and application prospects, will be more and more attention.

\section{Reference}

[1] Deutsch. Applications of Data Mining to Electronic Commerce - Springer[J]. Springer Us.

[2] Liu Z D. Enterprise Electronic Commerce Data Mining Analysis and Methodology[J]. Coal Technology, 2012.

[3] Wang X, Xu R, Wang W. Rough Set Theory: Application in Electronic Commerce Data Mining[C]. Web Intelligence, 2004. WI 2004. Proceedings. IEEE/WIC/ACM International Conference on. IEEE Xplore, 2004:541-544.

[4] Astudillo C, Bardeen M, Cerpa N. Editorial: data mining in electronic commerce - support vs. confidence[J]. Journal of Theoretical \& Applied Electronic Commerce Research, 2014, 9(1):I-VII.

[5] Chen G. Application of Web Data Mining Technique to Enterprise Management of Electronic Commerce[C]. Seventh International Symposium on Computational Intelligence and Design. IEEE, 2014:154-157.

[6] Li X, Zhao R, Xiao Y. Electronic Commerce Data Mining using Rough Set and Logistic Regression[J]. Journal of Multimedia, 2014, 9(5).

[7] Li P R. Application of data mining technology in electronic commerce[J]. Journal of Jiamusi Vocational Institute, 2016.

[8] Rad M P, Mirnabibaboli M. Optimized roles and data mining methods in electronic commerce and e-government for increasing the efficiency[J]. Journal of Emerging Technologies in Web Intelligence, 2014, 6(4).

[9] Wang P. Research on the Mechanism of Web Data Mining in Electronic Commerce Application[J]. Applied Mechanics \& Materials, 2014, 687-691:3003-3006.

[10]Ma J. The Technology of Data Mining and Electronic Commerce[C]. Third International Conference on Mechanic Automation and Control Engineering. IEEE Computer Society, 2012:3551-3553.

[11]Guang-Ji Y U. Applications of Data Mining Methods Based on Rough Sets in Electronic Commerce[J]. Journal of Dongguan University of Technology, 2013.

[12]Chen P P, Tan D Y, Liu X F. Research and Achievement of Customized Services in Electronic Commerce Based on Data Mining[J]. Advanced Materials Research, 2012, 546-547:452-457. 